\title{
Detection Of Pendimethalin and Cypermetrin Residues in Locally Produced Tomato Using QuEChERS-HPLC Analysis
}

\author{
${ }^{* 1}$ L. B. Abdulra'uf, ${ }^{1}$ F. A. Adeyemo, ${ }^{1}$ F. B. Atanda, and ${ }^{2}$ A. R. Lawal \\ ${ }^{1}$ Department of Chemistry, College of Pure and Applied Sciences, Kwara State University, Malete,P. M. B. 1530, llorin, Nigeria \\ ${ }^{2}$ School of Basic and Remedial Studies, Kwara State College of Education, P. M. B. 1527, Ilorin, Nigeria \\ [Corresponding Author: E-mail: abdulrauf.bola@kwasu.edu.ng; $\mathbf{8} 08139035676]$
}

\begin{abstract}
This study investigated the levels of pendimethalin and cypermetrin residues in tomato sold in Malete market, Moro Local Government Area of Kwara State. Tomatoes were randomly collected from five different vendors in Malete market and analysis was performed using the QuEChERS (Quick, Easy Cheap, Effective, Rugged and Safe) method followed by chromatographic analysis using high performance liquid chromatography (HPLC) coupled to ultra-violet (UV) detector. Method validation of the study showed a linearity of the analytes which ranges from $5-500 \mu \mathrm{g} / \mathrm{kg}$, with correlation coefficients greater than 0.999 . The average recovery ranges from 75.6 to $111 \%$ with relative standard deviation (RSD) from 2.74 to 9.03 $\%$. The results indicated the presence of cypermethrin in analyzed samples at concentrations lower than the permissible maximum residue levels.
\end{abstract}

Keywords: Sample preparation, Pesticide residues, HPLC-UV, QuEChERS.

\section{INTRODUCTION}

In order to increase food production, many types of pesticides including herbicides have been developed. Pesticides are used to control pests and plant diseases that can cause to damage plants and reduce agricultural production (Fenoll et al., 2007). The need for increase in agricultural food production is due to the greater demands for food, by the ever increasing world population (Abdulra'uf et al., 2012a).

Pendimethalin (N - (1 - ethylpropyl) - 3, 4 dimethy - 2, 6 - dinitrobenzenamine), a member of 2, 6 dinitro aniline herbicides, is widely used as a pre-emergence herbicide for selective control of weeds in crops (Tandon, 2008). Cypermethrin ( $R$ $S)$ - alpha-cyano - 3 - phenoxybenzyl (1RS) cis, trans - 3 - (2, 2-dichlorovinyl) - 2, 2 dimethylcyclopropanecarboxylate, is an alphacyano type II pyrethroid, which has been found to cause neurotoxicity in mammals and insects, is also used as insecticide due to their high insecticidal potency and relatively few side effects on birds and mammals (Muccio et al., 1997). Cypermetrhin has long rudimental time and undergoes relatively rapid biotransformation and excretion in mammals (Cheng et al., 2009; Zhang et al., 2009).
The continued use of these pesticides in agriculture has resulted in environmental pollution and their bioaccumulation in the food chain. Due to their uses and potential harm to public health, several organizations including the Food and Agricultural Organization, the World Health Organization established and Codex Alimentarius Commission, the European Union Council Directives (European Union, 2011, 2012), set the Maximum Residue Level (MRL) for pesticides and other contaminants in food of plant and animal origin. The Codex Committee on Pesticide Residues and other regulatory standards were established based on an international legal framework guiding the trade and use of pesticides (Abdulra'uf et al., 2016). Therefore, there is a need to develop an effective and efficient analytical method to determine their presence in food and the environment in order to determine if their presence conforms to the set limits of MRL.

Several methods have been developed for the analysis of pesticide residues in fruit and vegetable and most of these methods rely on solvent extraction and cleanup process which is time consuming and make use of toxic solvents. Microextraction techniques such as solid phase 


\section{Nigerian Journal of Basic and Applied Science (June, 2019), 27(1): 34-40}

microextraction, SPME (Arthur et al., 1992), microextraction in packed sorbent, SBSE (AbdelRehim, 2004), liquid phase microextraction, LPME (Abdulra'uf et al., 2012b) were developed to reduce or completely eliminate the use of toxic solvent, and these methods were found to be environmentally friendly and required less time however with some limitations (Sarafraz-Yazdi and Amiri, 2010).

Quick, Easy, Cheap, Effective, Rugged and Safe (QuEChERS) method (Anastassiades et al., 2003) developed recently is also less time consuming, with high selectivity and sensitivity, has gained popularity due to its safety, simplicity, affordability, effectiveness and efficiency (Sirhan et al., 2011). In the present study, a simple, affordable, and reliable extraction method is developed for the analysis of cypermethrin and pendamethalin in tomato samples, using high performance liquid chromatography coupled to ultra violet detector (HPLC-UV). This choice of pesticides was informed by the fact that they are widely used by vegetable farmers in Ilorin, Kwara State, Nigeria.

\section{MATERIALS AND METHODS Reagents and Solutions}

Cypermethrin and Pendimethalin standards of analytical grade $(99 \%)$ at $100 \mu \mathrm{g} / \mathrm{mL}$ were purchased from Sigma Aldrich (St. Luis, MO, USA). A working standard solution containing the pesticides was prepared daily by diluting the stock standard in methanol to a concentration of $10 \mu \mathrm{g} / \mathrm{mL}$ and kept at $4{ }^{\circ} \mathrm{C}$ before use. Aliquot of $50 \mu \mathrm{L}$ of the working standard solution was used to spike $5 \mathrm{~mL}$ of water for method development. A $5 \mathrm{~g}$ of the sample matrix was also spiked with a known amount of the working standard solution to concentration between 50, 100 and $150 \mu \mathrm{g} / \mathrm{kg}$ used for method optimization and validation studies. A concentration range of $10-500 \mu \mathrm{g} / \mathrm{kg}$ was prepared directly in the sample matrix for calibration purpose and method validation.

\section{Sample Collection and Preparation}

All tomato samples were collected from Malete Markets for multi-residue and multiclass pesticide residues analysis and the sample where kept in a freezer at $4^{\circ} \mathrm{C}$ prior to analysis. The samples used for calibration and recovery studies were first analyzed to ensure the absence of the target pesticide residues (Cortés-Aguado et al., 2008). For modified QuEChERS method, $100 \mathrm{~g}$ of prewashed tomato sample was weighed, finely chopped and homogenized using a blender. Then $5 \mathrm{~g}$ aliquot of the homogenized sample was placed in a separate $20 \mathrm{~mL}$ polypropylene tube and left for $1 \mathrm{hr}$ at room temperature. This was followed by addition of $10 \mathrm{~mL}$ of acetonitrile and was manually shaken for 1 minute. $\mathrm{MgSO}_{4}(2 \mathrm{~g})$ and $0.5 \mathrm{~g}$ of $\mathrm{NaCl}$ were then added and shaken after which the mixture was centrifuged for 5 minutes at $5000 \mathrm{rpm}$. The supernatant was collected and filtered with a $45 \mu \mathrm{m}$ polypropylene syringe filter. Exactly $20 \mu \mathrm{L}$ of the filtrate was then injected into the HPLC.

\section{HPLC Analysis}

A bulk scientific HPLC (BLC2O series) isocratic system coupled to UV-detector with variable wavelength, located in the Chemistry Department of Kwara State University, Malete, was used for the analysis of extracted pesticides. Chromatographic separation was carried out on Pinnacle DBAQ $\mathrm{C}_{18}$ column $(250 \times 4.6 \mathrm{~mm}$ i.d, $5 \mu \mathrm{m})$ Restek USA. HPLC analyses were performed at room temperature with a flow rate of $1 \mathrm{~mL} / \mathrm{min}$ and injection volume of $20 \mu \mathrm{L}$. The detector wavelength was set at $290 \mathrm{~nm}$. The mobile phase constituted methanol-water $(80: 20$, $\% v / v)$, three (3) replicate injections were made for each sample and calibration curves were derived from a matrix matched solution. The average area of the elution peaks were plotted against the standard concentrations.

\section{Method Validation}

Method validation is a quality assurance step, which is used to determine if the in-house method developed is suitable for its intended purpose. It is essential to ensure optimal utilization of 
analytical procedure (Chan, 2011). The analytical figures of merit were validated using external standard prepared in matrix-matched calibration standard. The calibration curve (Figure 1) of each pesticide was constructed using matrix sample spiked at eight different concentrations with the working standard solution. The prepared concentrations ranged from 5 to $500 \mu \mathrm{g} / \mathrm{kg}$, and the peak area obtained for each analyte and the external standard was used to construct a calibration curve by plotting the peak area of each analyte as a function of concentration. Each concentration point was analyzed in triplicate in three different sample matrices. The intra- and inter-day precision, accuracy, selectivity and sensitivity, limit of detection (LOD), limit of quantitation (LOQ) and average recovery were determined briefly defined as follows:

Intra- and Inter-day precision describe the closeness or agreement between a series of independent measurement obtained when an analytical method is applied in replicate to multiple sampling of homologous samples specified in terms of relative standard deviation (RSD). Intra-day precision describes the precision under the same experimental condition over a short period of time, while inter-day precision describes precision obtained under the same experimental condition carried out on different days. The intra-day precision was determined by performing three extractions in single day, while inter-day precision was determined based on three extractions per day for three days. A one-way single factor ANOVA was used to estimate the variance, which gives the total sum of square, between group mean square (BMS) and within group mean square (WMS). The BMS estimate the variance associated with the intra-day precision (withinday) and inter-day precision (between-day) variances:

$$
\begin{aligned}
& \% R S D(\text { Intra }- \text { day })=\frac{\sqrt{W M S}}{\text { Average Relative Recovery }} \times 100 \\
& \% R S D(\text { Inter }- \text { day })=\frac{\sqrt{\left(\frac{B M S-W M S}{N}\right)+W M S}}{\text { Average Relative Recovery }} \times 100
\end{aligned}
$$

Where: RSD = relative standard deviation; WMS = within group mean square; BMS = between group mean square; $\mathrm{N}=$ Number of replicate

$\mathrm{LOQ}$ is the lowest concentration of analyte that can be quantitatively determined with an acceptable level of accuracy and precision. LOD is the lowest concentration of analyte that can be detected but not necessarily quantified as an exact value under the optimized experimental conditions (ICH-Topic Q2 (R1), 2006). The LOQ was estimated based on the signal-to-noise ratio of 10:1, while the LOD was estimated based on the signal-to-noise ratio of $3: 1$ both of which were calculated using the following equations:

$$
L O Q=\frac{10 \sigma}{S} \quad L O D=\frac{3 \sigma}{S}
$$

Where $\sigma$ is the standard deviation of the response; $\mathrm{S}$ is the slope of the calibration curve.

\section{RESULTS AND DISCUSSION Analytical Method Validation}

Analytical methods was validated in terms of linearity, accuracy, intra- and inter-day precision, limit of detection (LOD) and limit of quantification (LOQ) using the optimized parameters.

\section{Linearity and Calibration Curve}

The calibration parameters are as presented in Table 1. Linearity of the method was tested using standard solution of the target pesticides in concentration range of $5-500 \mu \mathrm{g} / \mathrm{kg}$ using a matrix-matched external standard calibration curve. The peak area was plotted against the concentration of the analyte. The calibration 


\section{Nigerian Journal of Basic and Applied Science (June, 2019), 27(1): 34-40}

curve (Figures 1a and 1b) were linear over the tested concentration with correlation coefficients greater than 0.99 .

\section{Limit of Quantitation (LOQ) and Limit of Detection (LOD)}

The LOQ and LOD determined using the standard deviation of the $y$-intercept of the regression line is shown in Table 1 . The LOQ was found to be 12.06 and $21.04 \mu \mathrm{g} / \mathrm{kg}$, while the LOD was 3.62 and $6.31 \mu \mathrm{g} / \mathrm{kg}$, for pendimethalin and cypermethrin respectively. The figures of merit obtained in this study were found to be comparable with values reported in related studies for the analysis of pesticide residues in fruits and vegetables using different extraction techniques (Abdulra'uf et al., 2012a)..

Table 1: Linearity and Calibration Parameters

\begin{tabular}{lccllll}
\hline Pesticide & $\begin{array}{l}\text { Linear } \\
\text { Range } \\
(\mu \mathrm{g} / \mathrm{kg})\end{array}$ & $\begin{array}{l}\mathrm{LOQ} \\
(\mu \mathrm{g} / \mathrm{kg})\end{array}$ & $\begin{array}{l}\mathrm{LOD} \\
(\mu \mathrm{g} / \mathrm{kg})\end{array}$ & $\begin{array}{l}\mathrm{MRL} \\
(\mu \mathrm{g} / \mathrm{kg})\end{array}$ & Linearity curve equation & $\mathrm{r}^{2}$ \\
\hline Pendimethalin & $5-500$ & 12.06 & 3.62 & 50 & $\mathrm{y}=19.692 \mathrm{x}+202.85$ & 0.9998 \\
Cypermethrin & $5-500$ & 21.04 & 6.31 & 500 & $\mathrm{y}=20.069 \mathrm{xx}+49.307$ & 0.9995 \\
\hline
\end{tabular}

LOQ (limit of quantitation); LOD (limit of detection); MRL (maximum residue level)

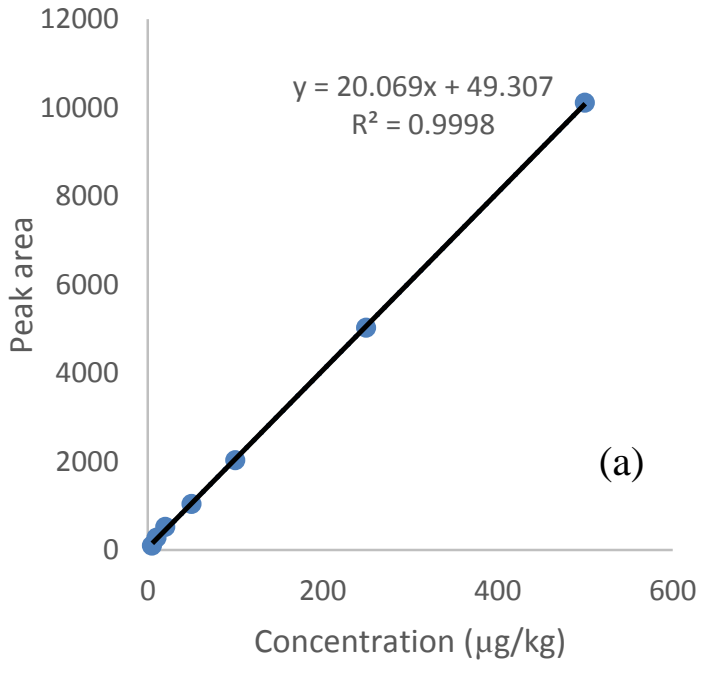

Figure 1: Calibration Curves of (a) Pendimethalin and
Recovery, Intra- and Inter-day Precision

The accuracy of the developed method was determined by estimation of the recovery of the selected pesticides spiked in the tomato matrix using three different concentrations $(50,100$ and $150 \mu \mathrm{g} / \mathrm{kg}$ ) and analysed in triplicate. As shown in Table 3 , the relative recovery of the spiked sample ranged from 75.6 to $111 \%$ which falls within acceptable limits according to SANCO guidelines (SANCO, 2011).

The results obtained for the recovery and precision studies were in accordance with acceptable practice (ICH-Topic Q2(R1), 2006)..

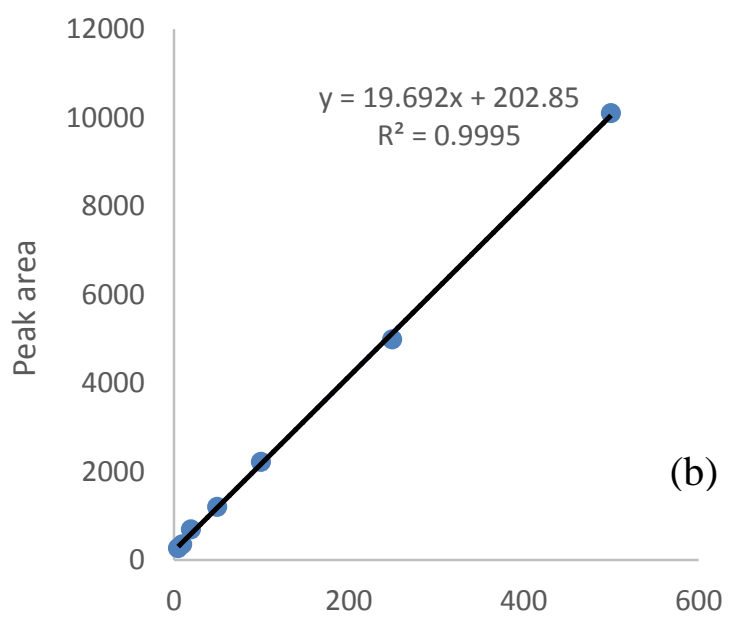

Concentration $(\mu \mathrm{g} / \mathrm{kg})$ (b) Cypermethrin

However, better recovery and precision were achieved at higher spiked level. All parameters were validated based on the method validation parameters of the European Union (SANCO, 2011).

Also presented in Table 3 is the precision of the developed method. The intra-day precision ranged from $2.74-8.54 \%$ and $4.86-5.84 \%$ for pendimethalin and cypermethrin respectively, while the inter-day precision was found to range between $2.98-9.03 \%$ and $4.74-6.03 \%$ for pendimethalin and cypermethrin respectively, calculated based on the analysis of variance presented in (Tables $2 a$ \& 2b.) 
Table 2: Summary of analysis of variance for (a) pendimethalin and (b) cypermethrin

\begin{tabular}{lllllll}
\hline (a) Pendimethalin & & & & & & \\
\hline Groups & Count & Sum & Average & Variance & & \\
Column 1 & 3 & 278 & 92.666 & 50.333 & & \\
Column 2 & 3 & 281 & 93.666 & 65.333 & & \\
Column 3 & 3 & 296 & 98.666 & 69.333 & & \\
& & & 95.9993 & & & \\
ANOVA & & & & & & \\
Source of Variation & SS & $d f$ & MS & F & F crit \\
Between Groups & 62 & 2 & 31 & 0.5027 & 0.6282 & 5.1432 \\
Within Groups & 370 & 6 & 61.6666 & & & \\
Total & 432 & 8 & & & & \\
\hline (b) Cypermethrin & & & & & & \\
\hline Groups & Count & Sum & Average & Variance & & \\
Column 1 & 3 & 139 & 46.333 & 1.333 & & \\
Column 2 & 3 & 136 & 45.333 & 9.333 & & \\
Column 3 & 3 & 131 & 43.666 & 4.333 & & \\
& & & 45.111 & & & \\
ANOVA & & & & & & \\
$\quad$ Source of Variation & SS & df & MS & F & & \\
Between Groups & 10.8889 & 2.0000 & 5.4444 & 1.0889 & & \\
Within Groups & 30.0000 & 6.0000 & 5.0000 & & & \\
Total & 40.8889 & 8.0000 & & & & \\
\hline
\end{tabular}

Table 3: Accuracy, Intra-and Inter-day Precision of the Developed Method

\begin{tabular}{|c|c|c|c|c|}
\hline Pesticide & $\begin{array}{c}\text { Spike } \\
d \\
(\mu \mathrm{g} / \mathrm{kg} \\
\quad\end{array}$ & $\begin{array}{c}\text { Recover } \\
y \\
\text { Accurac } \\
\mathrm{y}(\%) \\
\end{array}$ & $\begin{array}{c}\text { Intra } \\
- \\
\text { RSD } \\
(\%) \\
\end{array}$ & $\begin{array}{c}\text { Inter } \\
- \\
\text { RSD } \\
(\%) \\
\end{array}$ \\
\hline \multirow{2}{*}{$\begin{array}{l}\text { Pendimethali } \\
n\end{array}$} & 50 & 96.8 & 2.74 & 2.98 \\
\hline & $\begin{array}{l}100 \\
150\end{array}$ & $\begin{array}{c}85.6 \\
105\end{array}$ & $\begin{array}{l}8.26 \\
8.54\end{array}$ & $\begin{array}{l}7.74 \\
9.03\end{array}$ \\
\hline \multirow[t]{2}{*}{$\begin{array}{l}\text { Cypermethri } \\
\mathrm{n}\end{array}$} & 50 & 90.8 & 4.96 & 4.98 \\
\hline & $\begin{array}{l}100 \\
150\end{array}$ & $\begin{array}{c}75.6 \\
111\end{array}$ & $\begin{array}{l}4.86 \\
5.84\end{array}$ & $\begin{array}{l}4.74 \\
6.03\end{array}$ \\
\hline
\end{tabular}

The average recoveries and inter- and intra-day relative standard deviation were found to be acceptable according to the SANCO guideline (SANCO, 2011), which stated that the method performance criteria of average recovery should be in the range of $70-120 \%$ with relative standard deviation (RSD) less than or equal to $20 \%$ (SANCO, 2011).

\section{Analysis of Real Sample}

The presence of cypermethrin in all the tomato samples analyzed but were found to be below the maximum residue levels, while pendimethalin were not detected. The absence of pendamethalin could be as a result of the fact that it was used as a pre-emergence herbicide and must have been transported to the subsoil. The use and sales of pesticides is controlled and monitored by National Agency for Food and Drug Administration and Control (NAFDAC) in Nigeria. The agency adopts the CODEX limits and (when necessary) the MRLs of the importing country (Keri, 2009). 


\section{Nigerian Journal of Basic and Applied Science (June, 2019), 27(1): 34-40}

\section{CONCLUSION}

A simple, rapid and inexpensive sample preparation procedure using QuEChERS technique has been successfully developed. This is based on partitioning of the target analyte in acetonitrile /water mixture. It can be recommended as an alternative method to timeconsuming and multistep solid phase extraction method. The study revealed the presence of cypermethrin in all the analyzed real samples, while pendimathalin was not detected in the samples. The detected pesticide was found at concentrations lower than the maximum residue levels. This shows that the farmers have been using the pesticides based on the recommended dosage and therefore the tomatoes sold in Malete market are save for consumption.

\section{ACKNOWLEDGEMENTS}

The authors are grateful to the Kwara State University, Malete, for providing the analytical instruments used to conduct this study. The effort of Mr. Ayobami Idiaro is gratefully acknowledged.

\section{REFERENCES}

Abdel-Rehim, M. (2004). New trend in sample preparation: on-line microextraction in packed syringe for liquid and gas chromatography applications: In. Determination of local anaesthetics in human plasma samples using gas chromatography-mass spectrometry. Journal of Chromatogagraphy B, 801(2): 317-321.

Abdulra'uf, L.B., Chai, M.K. and Tan, G.H. (2012a). Applications of solid-phase microextraction for the analysis of pesticide residues in fruits and vegetables: A review. Journal of Association of Official Analytical Chemists International, 95(5): 12721290.

Abdulra'uf, L.B., Ibrahim, H.B., Lawal, A.R. and Tan, G.H. (2016). Pesticide use: Properties and environmental fate. AlHikmah Journal of Pure Applied Science, 3: $22-29$

Abdulra'uf, L.B., Sirhan, A.Y. and Tan, G.H. (2012b). Recent developments and applications of liquid phase microextraction in fruits and vegetables analysis. Journal of Separation Science, 35(24): 3540-3553.

Anastassiades, M., Lehotay, S.J., Stajnbaher, D. and Schenck, F.J. (2003). Fast and easy multiresidue method employing acetonitrile extraction/partitioning and "dispersive solid-phase extraction" for the determination of pesticide residues in produce. Journal of Association of Official Analytical Chemists International 86(2): 412-431.

Arthur, C.L., Killam, L.M., Buchholz, K.D., Pawliszyn, J. and Berg, J.R. (1992). Automation and optimization of solidphase microextraction. Analytical Chemistry. 64:1960-1966.

Chan, C.C. (2011). Principles and practices of analytical method validation: validation of analytical methods is time-consuming but essential. Quality Assurance Journal 14: 61-64.

Cheng, J., Liu, M., Yu, Y., Wang, X., Zhang, H., Ding, L. and Jin, H. (2009). Determination of pyrethroids in porcine tissues by matrix solid-phase dispersion extraction and high-performance liquid chromatography. Meat Science 82: 407412.

Cortés-Aguado, S., Sánchez-Morito, N., Arrebola, F.J., Grenido Frenich, A. and Vidal, J.L.M. (2008). Fast screening of pesticide residues in fruit juice by solidphase microextraction and gas chromatography-mass spectrometry. Food Chemistry 107(3): 1314-1325.

European Union (2011). EU pesticides database, established in directives $\mathrm{EC} / 395 / 2005$, $E C / 148 / 2008$ and EC/839/2008. EU Directorate General for Health \& Consumers.

European Union (2012). Commission Regulation (EU) No 899/2012 of the European Parliament and of the Council. Official Journal of the European Union L 273/1, 6.10.2012. 
Fenoll, J., Hellın, P., Martı́nez, C.M., Miguel, M. and Flores, P. (2007). Multiresidue method for

analysis of pesticides in pepper and tomato by gas chromatography with nitrogen-phosphorus detection. Food Chemistry. 105: 711-719.

ICH-Topic Q2(R1). (2006). Validation of Analytical Procedures: Text and Methodology. U. S. Department of Health and Human Services.

Keri, H.J. (2009). Nigeria's status on pesticide registrsation and maximum residue levels. Workshop on pesticide maximum residue level (MRLs), Alexandria, Egypt.

Muccio, A. D., Pelosi, P., Barbini, D. A., Generali, T., Ausili, A., \& Vergori, F. (1997). Selective extraction of pyrethroid pesticide residues from milk by solidmatrix dispersion. . J.ournal of Chromatography A, 765: 51-60.

SANCO (2011). Method validation and quality control procedures for pesticide residues analysis in food and feed; SANCO/12495/2011.

Sarafraz-Yazdi, A. and Amiri, A. (2010). Liquidphase microextraction. TrAC, Trends in Analytical Chemistr,y 29(1): 1-14.
Sirhan, A.Y., Tan, G.H. and Wong, R.C.S.(2011). Method validation in the determination of aflatoxins in noodle samples using the QuEChERS method (Quick, Easy, Cheap, Effective, Rugged and Safe) and high performance liquid chromatography coupled to a fluorescence detector (HPLC-FLD). Food Control 22: 18071813.

Tandon, S. (2008). Persistance of pendimethalin in soil and potato tuber. Potato Journal 35(1-2): 100-102.

Zhang, J.-J., Zang, L.-G., Zhang, J.-E., Cui, G.W., Tang, B., Li, X.-Y. and Zhou, L. (2009). Determination of cypermethrin residues in Gingko biloba leaves by high performance liquid chromatography. Bulletin of Chem. Society of Ethopia 23(1): 97-100. 